\title{
Reopening schools without strict COVID-19 mitigation measures risks accelerating the pandemic
}

\section{Deepti Gurdasani*1, Nisreen A Alwan*2, Trisha Greenhalgh ${ }^{3}$, Zoë Hyde ${ }^{4}$, Luke Johnson², Martin McKee ${ }^{56}$, Susan Michie ${ }^{5,7}$, Kimberly A. Prather ${ }^{8}$, Sarah Rasmussen ${ }^{9}$, Stephen Reicher ${ }^{5,10}$, Paul Roderick ${ }^{2}$, Hisham Ziauddeen $^{9}$}

\section{*equal corresponding authors:}

Deepti Gurdasani, d.gurdasani@qmul.ac.uk

Nisreen A Alwan, N.A.Alwan@soton.ac.uk

On $22^{\text {nd }}$ February, the UK government announced schools in England would fully reopen on the $8^{\text {th }}$ March 2021. While returning to school as soon as possible is imperative for the education, social development, and mental and physical welfare of children, not enough has been done to make schools safer for students and staff.(1) Without additional mitigations, significant increases in transmission are likely, this time with more infectious and possibly more virulent variants, resulting in further lockdowns, school closures, and absenteeism. Even when schools were 'open', at points of high community transmission, 20\% of secondary school children were self-isolating, reaching $\sim 40 \%$ in deprived areas.

Arguments that schools do not contribute to community transmission and that the overall risk to children from COVID-19 is very small have meant that mitigations in schools have received low priority. Yet the evidence cited for these arguments has serious limitations (2,3). Primary and secondary school closures have been associated with substantial reductions in the effective reproduction number $(R t)$ across many countries and time periods,(4) including in England (5). In contrast, the prevalence of infection among 210 year-olds (2\%) and $11-16$ year-olds (3\%) rose above all other age groups before the 2020 Christmas break (6) (Figure 1). Both modelling and real-world data showing rising cases in regions where B.1.1.7 was prevalent during the November lockdown (when schools were open) $(7,8)$ suggest that opening all schools now without robust mitigatory measures in place will likely lead to $R$ t rising above 1 in almost all scenarios (8). At least 30,000 more COVID-19 deaths were estimated under the proposed reopening scenarios.(9) Data also show a higher risk of infection among teaching staff during even during February, despite fewer students being in school at this time (10). Recent school outbreaks in countries where the B.1.1.7 variant is prevalent are also concerning (11).

Although COVID-19 is unlikely to cause severe disease in children, preliminary longitudinal data suggest that $13 \%$ of $2-10$ year-olds and $15 \%$ of $12-16$ year-olds have at least one persistent symptom 5 weeks after

\footnotetext{
${ }^{1}$ Queen Mary University of London, UK

2 University of Southampton, UK

${ }^{3}$ University of Oxford, UK

${ }^{4}$ University of Western Australia, Australia

${ }^{5}$ Independent SAGE, UK

${ }^{6}$ London School of Hygiene and Tropical Medicine, UK

7 University College London, UK

${ }^{8}$ University of California San Diego, US

${ }^{9}$ University of Cambridge, UK

${ }^{10}$ University of St. Andrews, UK
} 
testing positive (12). Given uncertainty around the long-term health consequences of SARS-CoV-2 infection, it would be unwise to let the virus circulate in children, with consequent risk to their families. Reopening fully in the setting of high community transmission without appropriate safeguards risks depriving many children of education and social interaction again, worsening existing inequalities. By contributing to high community transmission, it also provides fertile ground for virus evolution and hence new variants.

Multi-layered mitigations can substantially reduce the risk of transmission within schools and into households (13). In the Appendix we outline a set of recommendations, in line with CDC guidelines (14) and practiced in many countries, to reduce the risk of transmission in schools and mitigate the impact of COVID-19 on children and families (Appendix, Panel, Figure 2). Making schools safer goes hand in hand with reducing community transmission, and is essential to allow schools to safely reopen and remain open.

\begin{tabular}{|c|c|c|c|}
\hline Physical distancing & $\begin{array}{l}\text { Protections for } \\
\text { students and staff }\end{array}$ & $\begin{array}{l}\text { Ventilation and face } \\
\text { coverings }\end{array}$ & $\begin{array}{l}\text { Support children } \\
\text { and families }\end{array}$ \\
\hline $\begin{array}{l}\text { General } \\
\text { - Traffic light system of risk } \\
\text { - Use remote/blended } \\
\text { learning to reduce footfall } \\
\text { During travel } \\
\text { - Keep travel bubbles } \\
\text { constant } \\
\text { - Stagger start and finish } \\
\text { times } \\
\text { - Avoid mixing (e.g. at school } \\
\text { gates) } \\
\text { - Open windows and wear } \\
\text { masks on transport } \\
\text { In classrooms } \\
\text { - Keep bubble size small } \\
\text { - Reduce movement among } \\
\text { bubbles } \\
\text { - Deploy additional staff to } \\
\text { bubbles }\end{array}$ & $\begin{array}{l}\text { Hand and surface } \\
\text { hygiene } \\
\text { - Provide hand washing } \\
\text { stations and hand } \\
\text { sanitisers } \\
\text { - Wash hands regularly } \\
\text { and at key points (e.g. } \\
\text { after using toilet) } \\
\text { Vaccination } \\
\text { - Account for exposure } \\
\text { alongside age and } \\
\text { disease related risk in } \\
\text { vaccine prioritisation } \\
\text { - Prioritising school staff } \\
\text { reduces educational } \\
\text { disruption due to staff } \\
\text { illness } \\
\text { Testing } \\
\text { - Do not assume tests } \\
\text { are } 100 \% \text { accurate } \\
\text { testing is in addition } \\
\text { instead of }\end{array}$ & $\begin{array}{l}\text { Ventilation } \\
\text { - Open windows and doors } \\
\text { - Teach outdoors (or in } \\
\text { large halls) wherever } \\
\text { possible } \\
\text { - Use CO2 monitors to } \\
\text { assess air quality } \\
\text { - Install HEPA filters with } \\
\text { air cleaning devices } \\
\text { - All physical education } \\
\text { outdoors } \\
\text { - No high-risk lessons (e.g. } \\
\text { singing, brass/wind } \\
\text { instruments) except } \\
\text { remotely } \\
\text { Face coverings } \\
\text { - Encourage masking in } \\
\text { children } \geq 5 y \text { (with } \\
\text { exemptions) } \\
\text { - Teach correct mask } \\
\text { fitting and use } \\
\text { - Remove masks only } \\
\text { when outdoors or eating } \\
\text { - Consider transparent } \\
\text { improve communication } \\
\text { mafe disposal/washing of } \\
\text { masks }\end{array}$ & $\begin{array}{l}\text { Support blended and } \\
\text { remote learning } \\
\text { - Allow optional remote } \\
\text { learning } \\
\text { - Support remote } \\
\text { learning } \\
\text { with technologies, } \\
\text { funding, practical } \\
\text { support and skills } \\
\text { training } \\
\text { - Provide for safe } \\
\text { delivery/pick-up of free } \\
\text { school meals } \\
\text { Ensure safeguarding of } \\
\text { at-risk children } \\
\text { Address the harms of } \\
\text { educational disruption } \\
\text { Support with isolation } \\
\text { Record educational } \\
\text { disruption alongside } \\
\text { grades } \\
\text { Provide mental health } \\
\text { support to children } \\
\text { schools) }\end{array}$ \\
\hline
\end{tabular}




\section{$\underline{\text { References }}$}

1. Department for Education. Schools coronavirus (COVID-19) operational guidance. February 2021. Available at: https://assets.publishing.service.gov.uk/government/uploads/system/uploads/attachment dat a/file/963541/Schools coronavirus operational guidance.pdf

2. Hyde Z. COVID-19, children and schools: overlooked and at risk. The Medical Journal of Australia. 2020

3. Hyde Z. Difference in SARS-CoV-2 attack rate between children and adults may reflect bias. Clinical Infectious Diseases. https://doi.org/10.1093/cid/ciab183. 2021

4. Haug N, Geyrhofer L, Londei A, Dervic E, Desvars-Larrive A, Loreto $V$ et al. Ranking the effectiveness of worldwide COVID-19 government interventions. Nature Human Behaviour 4, 1303-1312. 2020.

5. Scientific_Advisory_Group_for_Emergencies. Children's Task and Finish Group: update to 4th Nov 2020 paper on children, schools and transmission. UK; 2020. Available from https://assets.publishing.service.gov.uk/government/uploads/system/uploads/attachment data/file/94 8617/s0998-tfc-update-to-4-november-2020-paper-on-children-schools-transmission.pdf

6. Office_for_National_Statistics. Coronavirus (COVID-19) Infection Survey 2020 [Available from: https://www.ons.gov.uk/peoplepopulationandcommunity/healthandsocialcare/conditionsanddiseases/ datasets/coronaviruscovid19infectionsurveydata.

7. Volz E, Mishra S, Chand M, Barrett JC, Johnson R, Geidelberg L, et al. Transmission of SARS-CoV-2 Lineage B.1.1.7 in England: Insights from linking epidemiological and genetic data. MedRxiv. $4^{\text {th }}$ January 2021. url: https://www.medrxiv.org/content/10.1101/2020.12.30.20249034v2.full.pdf

8. Munday JD, Jarvis Cl, Gimma A, Wong KLM, van Zandvoort K, CMMID COVID-19 Working Group et al. Estimating the impact of reopening schools on the reproduction number 2 of SARS-CoV-2 in England, using weekly contact survey data. February 2021. url: https://cmmid.github.io/topics/covid19/reports/comix/schools/School\%20Reopening\%20\%20PreprintVersion.pdf

9. SPI-M-O. Summary of further modelling. February 2021 https://assets.publishing.service.gov.uk/government/uploads/system/uploads/attachment data/file/96 3565/S1130 SPI-M-O Summary of further modelling of easing restrictions.pdf

10. Riley S, Walters CE, Wang H, Eales O, Haw D, Walters CE et al. REACT-1 round 9 final report: Continued but slowing decline of prevalence of SARS-CoV-2 during national lockdown in England in February 2021. 2021. https://www.imperial.ac.uk/media/imperial-college/institute-of-global-healthinnovation/EMBARGOED-00.01-04-Feb-react1 $\mathrm{r} 9$ final preprint vs1.1.pdf 
11. Covid variant, Corzano: outbreak in the village, schools closed. Sky news. Lombardy. $3^{\text {rd }}$ February 2021. https://tg24.sky.it/milano/2021/02/03/variante-covid-corzano-brescia

12. Updated estimates of the prevalence of long COVID symptoms. $21^{\text {st }}$ January 2021. https://www.ons.gov.uk/peoplepopulationandcommunity/healthandsocialcare/healthandlifeexpectanci es/adhocs/12788updatedestimatesoftheprevalenceoflongcovidsymptoms

13. Lessler J, Grabowski MK, Grantz KH, Badillo-Goicoechea E, Metcalf JE, Lupton-Smith C et al. Household COVID-19 risk and in-person schooling. MedRxiv.

2021. https://doi.org/10.1101/2021.02.27.21252597

14. Centre for Disease Control. Operational strategy for reopening schools. Updated $2^{\text {nd }}$ March 2021. https://www.cdc.gov/coronavirus/2019-ncov/community/schools-childcare/index.html 


\section{Figure 1: Estimated SARS-CoV-2 prevalence in different age groups (Office for National Statistics Infection Survey)}

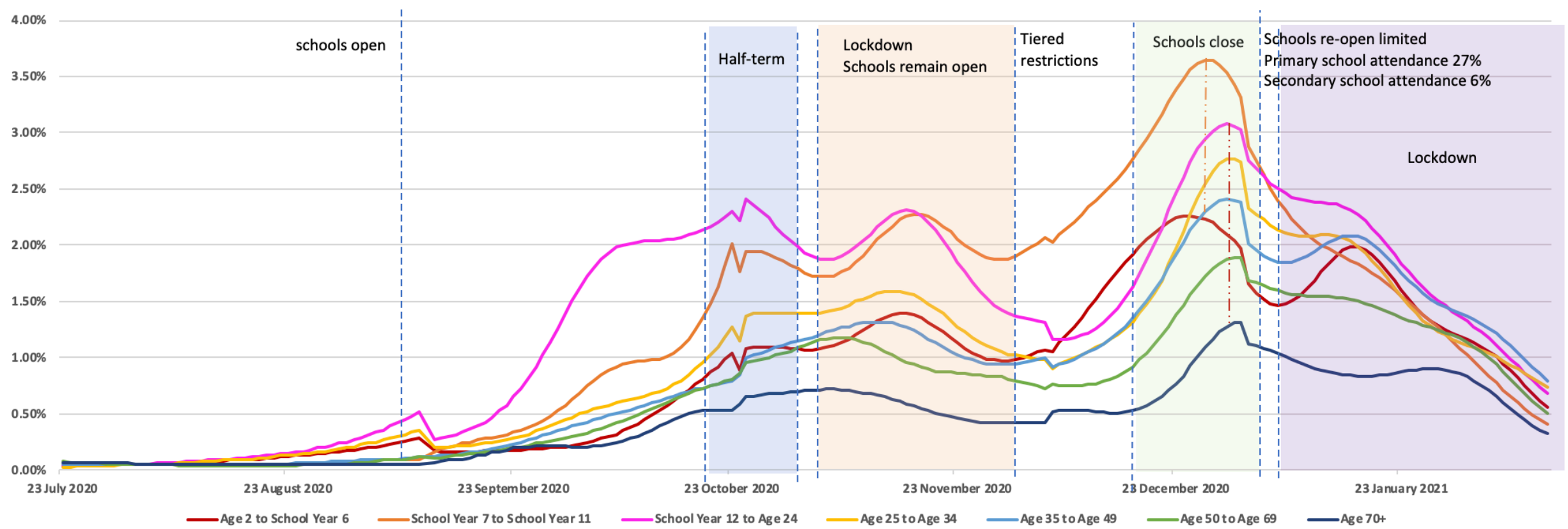

The figure shows the estimated prevalence of SARS-CoV-2 over time across different age groups based on the ONS Infection Survey. Infections in school age children broadly track school openings and closures. Infections rose sharply following school openings in September. They dropped during half-term in primary, secondary, higher education age groups, as well as in young adults, and rose again once schools opened. The Scientific Advisory Group for Emergencies (SAGE) has attributed this drop and rise to half-term school closures with moderate confidence. During lockdown, community infections fell in other age groups before dropping in school age children, suggesting that transmission in the school setting reduced as background community transmission fell. Infection rates rose sharply in primary school and secondary school age groups as lockdown was eased. At the end of the school term on the $18^{\text {th }}$ December, primary and secondary school children had the highest prevalence of infection across all age groups. Following school closures, infections declined in primary and secondary school children ahead of declines in all other age groups (peak of infection following school closure shown in orange and red dashed and dotted lines for school-age children, and other age groups). Following limited school re-opening, infections increased sharply in primary school children and adults aged $35-49$ years, in line with the higher attendance in primary schools $(27 \%)$ and early years settings $(61 \%)$, compared with secondary schools $(6 \%)$, where prevalence declined consistently. 
Figure 2: Recommendations for making schools safer

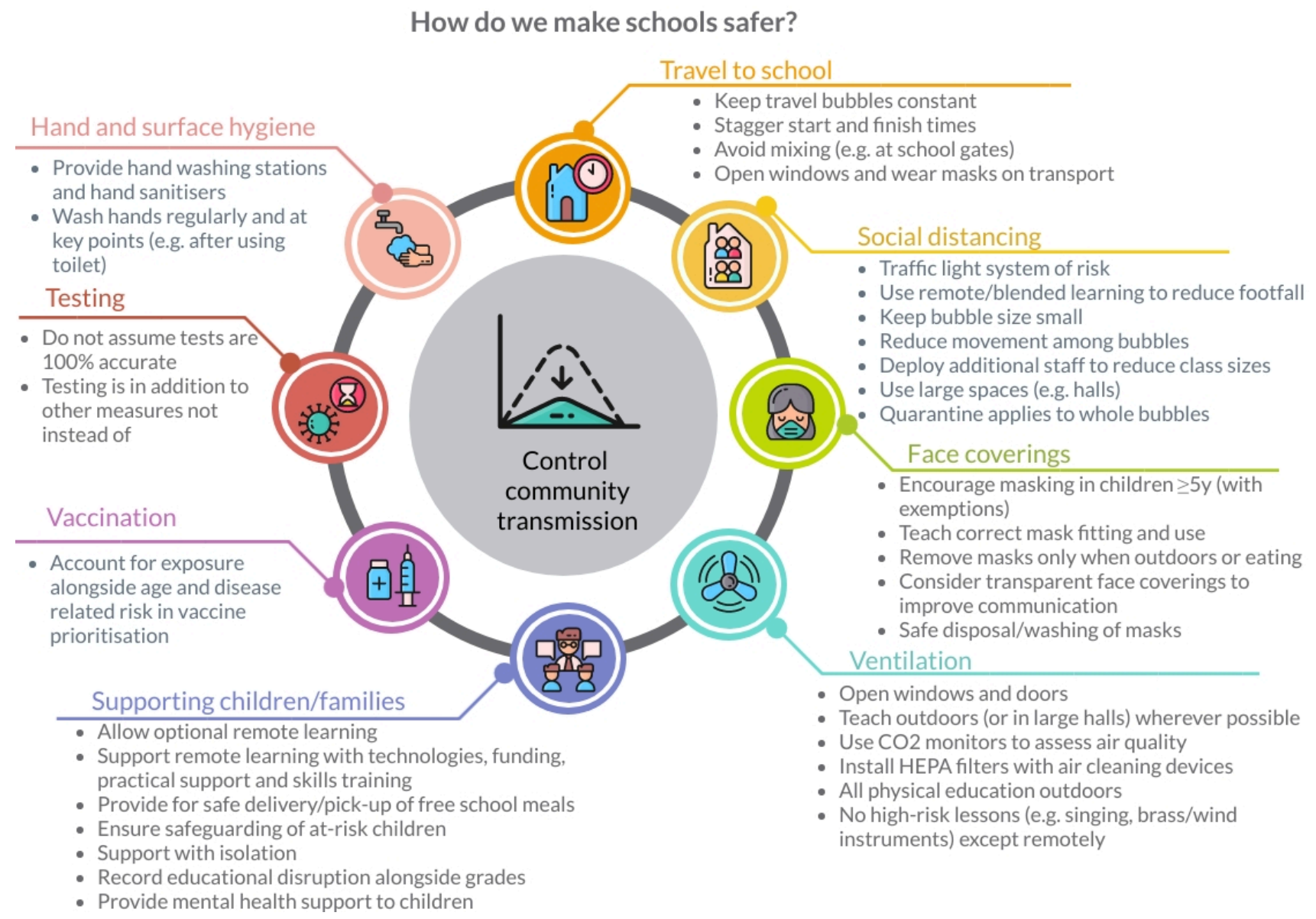


Appendix: Recommendations for making schools safer.

\section{Physical distancing}

1. Reduce mixing during travel to and while at school: Children should travel to school in family groups and/or small fixed social bubbles. Windows should be opened on buses/cars, and children should wear masks. Air should not be re-circulated. Where possible, schools should consider modifying start times to allow students who use public transport to avoid rush hour. Mixing at school gates should be minimised. Opening and closing times, class transitions and other activities that require use of shared spaces by large groups, should be staggered to reduce the level of mixing.

2. Reduce class sizes to allow physical distancing: This can be done through blended in-person and remote learning and use of currently unused large spaces such as churches and community centres, and outdoor marquees, when the weather allows. Bubbles of students and staff need to be manageable, and must be kept strictly apart. Bubble sizes should be capped (many schools have bubbles of several hundred) and teachers should minimise movement between bubbles. This will require recruitment of additional teaching and support staff.

3. Quarantine policies need to account for aerosol transmission: Transmission can occur at distances greater than those specified in physical distancing guidelines. All students sharing the bubble of a confirmed or suspected case should quarantine, contrary to current Department of Education guidance which suggests only students who were in close proximity to a case must quarantine (1). There will be less disruption when quarantine is required if bubble sizes are small (see also point 2).

\section{Protections for students and staff}

4. Test children in schools: Regular lateral flow and other rapid tests can be used to identify additional asymptomatic cases to break chains of transmission. The Department for Education guidance recommends twice a week testing for all staff and secondary school children (1). These are not a replacement for mitigatory measures and should not be used to replace quarantine of contacts of infected individuals, as this may increase infection risk. Schools must be supported adequately with testing, which should be conducted by those trained to do this well. Testing should be accompanied by re-emphasising the need for all mitigatory measures with clear public messaging about accuracy of tests so as to avoid providing false reassurance.

5. Prioritise those at high exposure risk for vaccination, including school staff: In order to maximise the chance of keeping classes and schools operating, school staff should be in the next prioritisation group for vaccination along with other frontline key workers. UK vaccine priority lists should be updated to include level of exposure as a risk factor, including for parents.

6. Hand and surface hygiene: Handwashing stations, and hand sanitisers should be made available throughout the school. Regular handwashing, and at key points, including entry into buildings, and toilet use should be encouraged.

\section{Ventilation and face coverings}

7. Ventilation of classroom and staff spaces: Open windows and doors whenever possible when teaching indoors. Good ventilation is vital and $\mathrm{CO}_{2}$ monitors should be used to gauge the efficacy of ventilation and balance it with thermal comfort. Where ventilation with outdoor air is not possible, measures should be taken to implement HEPA filtration with indoor air cleaning devices (2). Where 
possible, teaching and other activities should be moved outdoors or into larger spaces such as halls, taking advantage of the onset of spring and summer. Activities associated with a high-risk of aerosol transmission (e.g. singing or use of wind instruments) should be held outdoors, or replaced with safer alternatives. Physical education classes should always be held outdoors

8. Use of properly fitting face coverings by staff and students aged $\mathbf{5}$ years and above in all indoor spaces: This should take into account tolerability, health conditions and children's wellbeing. Consistent and correct use of masks, as well as safe disposal practices should be taught and reinforced. Masks should be provided regularly by the government, as has been done in other countries. Masks should only be removed when outdoors or eating. Eating should be done outside where possible. If this is not possible, lunch times should be staggered, with few children at a time in well-ventilated rooms. The use of transparent masks should be considered to improve communication.

\section{Mitigate inequalities and harms due to remote learning and educational disruption}

9. Support blended and remote learning: This will allow schools to move between in-person, blended and remote teaching as required and these decisions should be guided by a traffic light system, informed by epidemiological data not arbitrary dates. This has been suggested by Independent SAGE (3) and is in use in Israel (4), which, like the UK, has a rapid vaccine roll out. Parents should be allowed to opt for remote schooling, especially in the case of clinically vulnerable children or household members. Mandating in-person schooling has led to many parents having to de-register their children from school due to legitimate concerns about risk to themselves and their families, after being threatened with prosecution and fines, further contributing to inequities, and impacting mental health.

10. Protect and support vulnerable students: Socioeconomic inequalities in education should be addressed by providing adequate technological, financial and practical support for remote or rota learning when needed. There must be IT, wifi and study space provision for all, to support periods during which students need to quarantine or isolate. A large number of students still do not have access to these. For children who rely on school meals, there should be provisions for the safe pickup or delivery of school meals. Mental health support must be expanded in all schools. A Young Minds report showed that only $27 \%$ of students had been able to talk to anyone about how they were feeling when they returned to school (5). Every school should have sufficient counsellors for students to access support from. Children affected by abuse and domestic violence may be at increased risk when having to quarantine or isolate with their abuser. Schools should designate a qualified person in whom students can confide. Students and staff should be regularly reminded that they can speak with this person in a safe and confidential manner. Schools should ensure staff are aware of how to report suspected violence.

11. Address the harms caused by educational disruption: We need urgent action to recognise the harms of missing school for those who have experienced severe educational disruption and are graduating from school this summer. This should be recorded alongside grades and should be taken into account in the transition to jobs, colleges, and universities. There should also be enhanced skills provision (e.g. summer schools, foundation years) to provide the skills students have missed, so they can thrive in their new settings.

It is important to re-emphasise that making schools safer goes hand in hand with reducing community transmission to very low levels. Schools need ample resources, guidance, and support to implement adequate mitigation measures that focus on cleaning the shared indoor air over surfaces. Clearly, there 
are no easy or perfect solutions. This will be hard work but essential to protect community health and allow schools to safely reopen and remain open.(6)

\section{References}

1. Department for Education. Schools coronavirus (COVID-19) operational guidance. February 2021. Available

at:

https://assets.publishing.service.gov.uk/government/uploads/system/uploads/attachment dat a/file/963541/Schools coronavirus operational guidance.pdf

2. Allen J, Spengler J, Jones E, Cedeno-Laurent J. 5-step guide to checking ventilation rates in classrooms. Harvard T.H. Chan School of Public Health; 2020.

3. The Independent SAGE Report 34. The return to schools: A consultation document. February 2021 https://www.independentsage.org/wp-content/uploads/2021/02/Schools-consultation-Feb-2021-2.pdf

4. Ministry of Health, Israel. Covid-19 Guidance. https://www.gov.il/en/Departments/Guides/ramzor-cites-guidelines

5. Young Minds. Coronavirus impact on young people with mental health needs. Survey 3: Autumn 2020. Return to School. 2020. https://youngminds.org.uk/media/4119/youngminds-survey-with-youngpeople-returning-to-school-coronavirus-report-autumn-report.pdf

6. Lessler J, Grabowski MK, Grantz KH, Badillo-Goicoechea E, Metcalf JE, Lupton-Smith C et al. Household COVID-19 risk and in-person schooling. MedRxiv.

2021. https://doi.org/10.1101/2021.02.27.21252597 
